\title{
Special Issue on "Innovative Approaches for Decision Analysis in Energy, Health, and Life Sciences"
}

\author{
Martin Dlouhý • Stefan Pickl • Marion Rauner • \\ Ulrike Leopold-Wildburger
}

Published online: 14 July 2009

(C) Springer-Verlag 2009

The 22nd European Conference on Operational Research EURO2007 took place in Prague, Czech Republic, organised by the Czech Society of Operational Research and the University of Economics in Prague. The conference participants were researchers, academicians, and practitioners interested in operational research, mathematical modelling and quantitative economic analysis. The number of participants was higher than 2,000 persons form various countries of the world, making the Prague conference the largest EURO conference ever. The high number of conference participants is a sign promising that Operations Research (OR) is an attractive scientific discipline with many new theoretical developments and practical applications.

In 2005, a special issue of the Central European Journal of Operations Research has been devoted to quantitative decision support for health care (cf. CEJOR 2005).

This special issue is devoted to innovative approaches for decision analysis in energy, health, and life sciences. One may ask what these different topics have in common? The answer is that they represent key major challenging application fields for researchers that contain many measurement, definition, and interpretation problems which are complicated by dynamic and stochastic structure of the studied systems.

\footnotetext{
M. Dlouhý

University of Economics, Prague, Austria

S. Pickl

Universität der Bundeswehr München, Munich, Germany

M. Rauner ( $\varangle)$

University of Vienna, Vienna, Austria

e-mail: Marion.Rauner@univie.ac.at

U. Leopold-Wildburger

Karl-Franzens-University, Graz, Austria
} 
The objective of this special issue is to demonstrate that OR researchers are able to deal with such complex systems. Decision makers throughout the world face problems with scarce resources and more costly advanced technologies for energy and health care while the demand and prizes are increasing. These sectors are also highly interrelated. For example, clean water and energy for heating and coking are crucial survival factors in mankind.

Of course, in different sectors of economy, solutions can be different but analytical methods are the same and policies must be evidence-based and cost-effective to best allocate limited resources. The OR methods applied ranged from mathematical programming, Tabu search, Data Envelopment Analysis and Malmquist Approach, regression models, multicriteria optimization and multiobjective control to genetic network analysis. The authors are affiliated with universities and research institutions in Austria, France, Germany, Moldowa, the Philippines, Turkey, and USA.

First, we included four papers in the health care field: (1) planning of emergency medical services, (2) allocation of prevention time at general practitioners, (3) efficiency evaluation of public expenditures on health and education, and (4) influence of inpatient reimbursement systems on treatment patterns.

Roberto Aringhieri shows how mathematical programming can help improve efficiency and equity of emergency medical services of Milano, Italy. His paper focuses on optimization in decisions of the operation centre of emergency service that faces the problem of composing medical crews. Tabu searched algorithm used to solve this NP-hard problem.

Evrim Günes illustrates that allocating time for prevention at general practitioners is a non-linear optimization problem. Optimal allocation of preventive services depends on the slack capacity in the system and the relative cost of waiting and treatment.

Policy makers are increasingly concerned with efficiency of public expenditures. Rouselle Lavado and Emilyn Cabanda apply Data Envelopment Analysis, Free Disposal Hull, and Malmquist index to evaluate efficiency of public expenditures on health and education in the Philippines. Their work supports more effective budget allocation among provinces and identify provinces that could potentially achieve better health and educational outcome with the given level of expenditures.

The effect of the Austrian-performance oriented reimbursement system, called LKF-system, on treatment patterns is analyzed by Michaela Schaffhauser-Linzatti, Achim Zeileis, and Marion Rauner. Using regression models, they reveal that Federal State-specific reimbursement features together with Federal State-specific Big Ticket technologies such as magnetic resonance imaging and the age of the inpatients as the main influencing factors on average length of stay and average LKF-points.

In the second part, the decision analysis in energy and the lifesciences is treated in detail: (5) management decisions in a sustainable context, (6) energy planning in a multicriteria sense, (7) multiobjective control as a global method for the design and analysis of complex systems, (8) design and analysis of complex networks-special example gene-environment networks-, interdisciplinary implications and a survey on Operations Research and mathematical methods.

In the paper of Doris A. Behrens, Birgit Bednar-Friedl and Michael Getzner the sustainable management of an alpine national park is discussed. They handle the two- 
edged effect of tourism within the context of a national park's management decision and design an optimal policy mix.

Raphaele Thery and Pascale Zarate describe in their contribution energy planning as a complex issue because of its multi-scale and multicriteria issues. Especially, they regard energy supply chains as well as a state of the art at classifying the underlying issues.

In the contribution of Dmitrii Lozovanu and Stefan Pickl, a time-discrete system which might also occur in the energy sector is considered. The authors introduce a certain graph-theoretic structure and discrete optimal control problems to model the transitions of the time-discrete dynamical system. Algorithms for finding the optimal stationary control parameters are presented.

This approach can be used as a decision support strategy within such a class of problems; especially so-called multilayered decision problems which occur within environmental emission trading procedures can be modelled and solved by such an approach.

The design and analysis of a complex network is also in the center of interest of the last contribution. Gerhard-Wilhelm Weber, Erik Kropat, Basak Akteke-Özturk and Zafer-Korcan Görgülü present in their paper recent advances and a mathematical foundation of a further class of complex networks; namely so called gene-environment networks. They characterize interdisciplinary implications and draw special attention to applications in Operations Research and environmental protection.

We believe that all papers in this special issue satisfy high standards of CEJOR and show a wide application ability of operational research to analyze and optimize real-life energy and health systems.

Acknowledgements Editing this special issue was only possible by the support and effort of the authors and reviewers. We are also indebted to all sponsors such as Prof. Dr. Josef Jablonsky, the organizing committee's head of the EURO2007 conference at the University of Economics in Prague and the Prof. Dr. Wolf Rauch, Dean of the Faculty for Social and Economic Sciences of the Karl-Franzens-University, Graz, Austria. We are grateful for financial support of the Austrian Federal Ministry of Science and Research.

\section{Reference}

Central European Journal of Operations Research (CEJOR) (2005) Special issue on "Quantitative Decision Support for Health Services". In: Rauner MS, Behrens D, Wild C (eds) Central European Journal of Operations Research, vol 13, no. 4 